Finance and Economics Discussion Series Divisions of Research \& Statistics and Monetary Affairs Federal Reserve Board, Washington, D.C.

\title{
Rounding and the Impact of News: A Simple Test of Market Rationality
}

\section{Meredith Beechey and Jonathan $H$. Wright}

2007-05

NOTE: Staff working papers in the Finance and Economics Discussion Series (FEDS) are preliminary materials circulated to stimulate discussion and critical comment. The analysis and conclusions set forth are those of the authors and do not indicate concurrence by other members of the research staff or the Board of Governors. References in publications to the Finance and Economics Discussion Series (other than acknowledgement) should be cleared with the author(s) to protect the tentative character of these papers. 
Rounding and the Impact of News: A Simple Test of Market Rationality

Meredith Beechey and Jonathan H. Wright ${ }^{*}$

\begin{abstract}
Certain prominent scheduled macroeconomic news releases contain a rounded number on the first page of the release that is widely cited by newswires and the press and a more precise number in the text of the release. The whole release comes out at once. We propose a simple test of whether markets are paying attention to the rounded or unrounded numbers by studying the high-frequency market reaction to such news announcements. In the case of inflation releases, we find evidence that markets systematically ignore some of the information in the unrounded number. This is most pronounced for core CPI, a prominent release for which the rounding in the headline number is large relative to the information content of the release.
\end{abstract}

Keywords: News Announcements, Rounding, Market Efficiency, Rational Inattention. JEL Classification: E44, G14.

\footnotetext{
* Division of Monetary Affairs, Board of Governors of the Federal Reserve System, Washington DC 20551. We are grateful to David Lebow for helpful discussions and to Brian Bunker and Peter Eberhard for research assistance. The views in this paper are solely the responsibility of the authors and should not be interpreted as reflecting the views of the Board of Governors of the Federal Reserve System or of any other person associated with the Federal Reserve System.
} 


\section{Introduction.}

Market efficiency requires all available information to be reflected in asset prices. Although it is widely agreed that asset returns are somewhat predictable, it is not clear whether this reflects time-variation in discount rates or a failure of market efficiency, for which we have to look beyond standard rational asset pricing models. This debate is central to modern finance.

Occasionally, natural experiments arise that provide simple and direct tests of market efficiency (e.g. Lamont and Thaler, 2003). This note describes one such experiment. Scheduled macroeconomic news announcements represent the canonical mechanism by which public information is released. In the United States, these announcements are made under tightly controlled conditions. Many important releases come out at 8:30 am sharp. Reporters are given the text of the release and allowed to write their stories earlier, but are prevented from transmitting these stories until 8:30 am. The releases are extremely closely watched by the markets, and standard theory would predict that they should cause a jump in the prices of financial assets. And indeed, much empirical work on the reaction of asset prices to these news announcements finds a very sudden reaction.

Some important U.S. macroeconomic data releases include a rounded headline number that is reported on the first page of the release, and that is widely quoted in newswire stories, and then a more precise number in the text of the release. Importantly, the whole release comes out concurrently. If markets are efficient, they should react to the precise number. On the other hand, if they are not efficient, they may react to the headline number alone, ignoring the more complete information in the text of the release. 
In this paper, we propose a test of whether markets react to the rounded or unrounded numbers. We consider three releases for which the commonly reported rounded number is not the most precise information available - core CPI inflation, core PPI inflation, and the unemployment rate. For the core CPI, a prominent release for which the rounding in the headline number is large relative to the information content of the release, we find evidence that markets overlook some of the information in the unrounded numbers..

\section{Rounded and Unrounded News Announcements}

We first describe the rounding that applies to the release of the core CPI price index (and other Bureau of Labor Statistics (BLS) price indices). The price index is first rounded to one decimal point and this price index is reported in the text of the news announcement. More precise price index data are prepared by the BLS but not reported to the public, so for our purposes in studying market reactions, it is as though these data do not exist. ${ }^{1}$ The month-on-month percent change in the one-decimal precision published price index is computed, then rounded to the nearest tenth of a percentage point, and reported on the first page of the news announcement. This statistic is heavily reported by the press and newswire services. ${ }^{2}$

For example, the March 2006 CPI release showed the seasonally adjusted core CPI price index rising 0.3 percent from the prior month, and this headline number alone was reported in most press discussion of the release. A reader who reads on to page 12 of

\footnotetext{
${ }^{1}$ Recently, the BLS announced that starting with the January 2007 CPI release, the CPI price indices would be rounded to three decimal points, meaning that more precise information will be available to market participants in the future.

${ }^{2}$ Likewise, the unemployment and labor force numbers are given in the text of the employment situation release, measured in thousands of workers, and the implied unemployment rate is computed, rounded to the nearest tenth of a percentage point, and this number is reported on the first page of the announcement.
} 
the same release can, however, see that the March core CPI was 204.2, up from 203.5 in February, representing core CPI inflation of 0.344 percent, which only just rounds down to three tenths. ${ }^{3}$ A simple test of market efficiency is therefore given by considering whether or not the market on average reacts to the rounding error, which is -0.044 percent in this example.

We assume that if markets are efficient, the change in yields in a short window around the news announcement, $\Delta y_{t}$, will be a linear function of the unexpected component of the unrounded news announcement. That is,

$$
\Delta y_{t}=\alpha+\beta\left(x_{t}-E\left(x_{t}\right)\right)+\varepsilon_{t},
$$

where $x_{t}$ is the unrounded data (the data as recorded at the greatest precision available in the news release), $E\left(x_{t}\right)$ is the ex-ante expectation of this release, and $\varepsilon_{t}$ is an error term. If instead markets look only at the rounded data, we assume that

$$
\Delta y_{t}=\alpha+\beta\left(r\left(x_{t}\right)-E\left(x_{t}\right)\right)+\varepsilon_{t}
$$

where $r\left(x_{t}\right)$ denotes the rounded value of $x_{t}$ as reported on the first page of the news release and in newswire stories. Equations (1) and (2) can be nested in the model

$$
\Delta y_{t}=\alpha+\beta\left(x_{t}-E\left(x_{t}\right)\right)+\gamma\left(x_{t}-r\left(x_{t}\right)\right)+\varepsilon_{t}
$$

Under specification (1) (markets react to the most precise data available), $\gamma=0$. Under specification (2) (markets care only about the headline number), $\gamma=-\beta$. Intermediate cases are of course possible. The relationship between $\Delta y_{t}$ and $x_{t}$ is plotted in Figure 1 under both specifications (1) and (2). Note that some rational expectations models have

\footnotetext{
${ }^{3}$ While the true unrounded changed based on unrounded index levels cannot be observed, the precision number in the text of the release is the best possible estimate.
} 
recently been proposed in which changes in yields around news announcements could be a nonlinear function of the unexpected component of those announcements (e.g. Veronesi (1999)). However, equation (3) is simply a projection of yield changes on the unexpected component of the news announcement and the rounding error. We cannot imagine a rational expectations model in which the coefficient on the rounding error is nonzero.

The data announcements that we consider are core CPI inflation, core PPI inflation (hereon denoted as core CPI and core PPI, respectively) and the unemployment rate, each important macroeconomic news announcements produced by the BLS and released monthly at $8: 30 \mathrm{am}$ on a scheduled date. These data are never released on the same day. For each of these announcements $E\left(x_{t}\right)$, the ex-ante expectation of the release, is measured as the median expectation from the Money Market Services (MMS) survey taken the previous Friday. The actual value of the release is taken as the real-time announced value. For core CPI and the unemployment rate, the sample period is July 1991 to September 2006, for a total of 180 observations per regression. For core PPI, the sample period is April 1997 to September 2006. Prior to April 1997, the BLS published only the rounded number for seasonally adjusted core PPI inflation, not the corresponding price index, so we are unable to conduct our test before that date. Some summary statistics are reported in Table 1. The rounding error is economically substantial, especially in the case of core CPI - the standard deviation of the rounding error is about one third the size of the standard deviation of the surprise component of the release itself, so that the rounding is substantial relative to the information content of the release.

For each of the three types of news announcements that we consider, we estimate regressions of the form of equation (3) where $\Delta y_{t}$ represents the change in the two-year 
Treasury yield, the ten-year Treasury yield or a eurodollar futures rate ${ }^{4}$ from 8:25am to 8:40am on the days of announcements. Separate regressions are run for the core CPI, core PPI, and unemployment rate announcements, as the three announcements are never simultaneous. Other important scheduled news announcements can, however, come out at the same time as core CPI, core PPI or unemployment rate announcements. In particular, the widely watched change in nonfarm payrolls is always released at the same time as the unemployment rate. To control for this, we augment the regressions with the unexpected components of nonfarm payrolls, retail sales growth, and initial jobless claims announcements that come out concurrently. ${ }^{5}$

The results are shown in Table 2. The coefficients on the rounding error are significantly negative for core CPI for all three yield changes, meaning that investors react to the rounded headline number rather than to all the available information. Indeed, it is not possible to reject the null hypothesis that $\gamma=-\beta$, implying that markets focus exclusively on the rounded number.

The estimated coefficient on the rounding error for core PPI is not statistically significantly different from zero and the point estimate is positive (the 'wrong' sign given that a positive core PPI surprise causes yields to rise). The standard error is large. Such imprecision is not wholly unexpected as the rounding error is very small relative to the standard deviation of core PPI surprises. An alternative method is to estimate a common

\footnotetext{
${ }^{4}$ Specifically, we use the rate on the fourth eurodollar futures contract in the quarterly cycle, which is a futures contract on a three-month interest rate about one year hence.

${ }^{5}$ The unexpected components of these announcements are also measured using MMS survey expectations. Where no such announcement occurs, the unexpected component is set to zero.
} 
coefficient for surprises and rounding errors to core CPI and core PPI releases. ${ }^{6}$ To make the variables comparable and the common coefficient meaningful requires scaling the surprises and rounding errors by the standard deviation of surprises of the respective variable. In this way, the common surprise coefficient measures the response of asset markets to a one-standard deviation surprise and the common rounding-error coefficient measures the response to a similarly standardized unit of rounding. ${ }^{7}$ Estimating over the sample from April 1997 (our start date for core PPI), the joint coefficient on the rounding errors is found to be negative and strongly significantly different from zero for two- and ten-year yields and eurodollar futures rates, as shown in Table 3. In addition, one cannot reject the null hypothesis for the joint coefficients that $\gamma=-\beta$ at conventional levels of significance.

In the unemployment regression, the estimated coefficient on the rounding error is not significant but the point estimate is positive, which is the expected sign if markets focus only on the rounded number, given that on average higher-than-expected unemployment causes yields to fall. The unemployment rate is always released concurrently with the employment report, which receives much more market attention. While we control for the unexpected component of the nonfarm payrolls release in the unemployment regression, it is possible that news about unemployment can be

\footnotetext{
${ }^{6}$ This is a plausible strategy as one cannot reject at conventional levels of significance the null hypothesis that the responses of assets to a one-standard deviation surprise to core CPI and core PPI surprises are the same size, nor the hypothesis that the coefficients on standardized rounding errors are the same.

${ }^{7}$ It is important that the rounding error is calculated from the original release and then scaled by the standard deviation of surprises.
} 
overshadowed by the employment report, especially on days when the payrolls surprise is big. $^{8}$

Overall, the effect of rounding seems most important for the core CPI, this being the release for which the rounding error is largest relative to the size of the data surprise. The large standard deviation of core PPI surprises hinders estimation of that variable but when combined with core CPI rounding errors, the joint coefficient is significantly negative and we cannot reject the hypothesis that markets focus exclusively upon the rounded numbers.

\section{Imprecision of Survey Expectations - a Monte Carlo approach}

It is standard in the macroeconomic news announcement literature to use MMS surveys to measure agents' expectations for upcoming releases, and the available statistical evidence is quite strong that these surveys correctly measure conditional expectations (see, for example, Balduzzi, Elton and Green, 2001). Still, there is presumably some measurement error in these expectations, and the median survey expectations for core CPI, core PPI, and the unemployment rate respectively are rounded and recorded to the nearest tenth of a percentage point. We were concerned about biases and size distortions that could be induced in our test by this measurement error and rounding.

To investigate this, we did some Monte-Carlo simulations. The design of the experiment is as follows:

\footnotetext{
8 Indeed, when we exclude days on which the nonfarm payrolls surprise was bigger than 150,000 in absolute magnitude, the coefficient on the unemployment rounding error becomes positive with a $\mathrm{p}$ value of 0.07 . Doing so excludes 26 of the 176 observations in this regression.
} 
(i) We simulated random draws of artificial unrounded released data, $x_{t}$, that are iid $N\left(e_{t}, \sigma_{x}^{2}\right)$ where $e_{t}$, the simulated expectation of the data, is itself drawn from an iid $N\left(\mu, \sigma_{e}^{2}\right)$ distribution.

(ii) The simulated survey expectation of the data is given by $s_{t}=r\left(e_{t}+m_{t}\right)$, where $m_{t}$ is iid $N\left(0, \sigma_{m}^{2}\right)$ and so is equal to the sum of the expectation $e_{t}$ plus zero-mean measurement error, and is then subject to rounding.

(iii) The simulated change in yields is $\Delta y_{t}=\beta\left(x_{t}-e_{t}\right)+u_{t}$ where $u_{t}$ is iid $N\left(0, \sigma_{u}^{2}\right)$ and the population R-squared from this regression is $R_{P O P}^{2}=1-\frac{\sigma_{u}^{2}}{\beta^{2} \sigma_{x}^{2}+\sigma_{u}^{2}}$.

All of the errors in this model are mutually independent and the sample size is $T$. We then ran the regression

$$
\Delta y_{t}=\alpha+\beta\left(x_{t}-s_{t}\right)+\gamma\left(r\left(x_{t}\right)-x_{t}\right)+\varepsilon_{t}
$$

in each of 10,000 replications, and computed the rejection rates of a 5-percent two-sided test of the hypothesis that $\gamma=0$ using heteroskedasticity-robust standard errors. The null hypothesis is true in this design, so we are simulating the empirical size of the test. The results are numerically invariant to the choice of $\mu$ (because it is differenced out in equation (4)) and we normalize $\beta$ to equal 1 (which amounts to setting the units in which yield changes are measured). This leaves five parameters: $\sigma_{x}, \sigma_{e}, \sigma_{m}, R_{P O P}^{2}$, and the sample size $T$.

Table 4 reports the simulated rejection rates for a wide range of choices of these parameters. Our choices of $\sigma_{x}$ and $\sigma_{e}$ comfortably span the corresponding sample variances for core CPI, core PPI, and the unemployment rate reported in Table 1. The 
population $\mathrm{R}^{2}$ ranges from 0 to 40 percent, which likewise easily brackets the degree of predictability of yield changes in the wake of these news announcements that we and others have found. The sample size is set to 100 or 200 , again in line with our application. Finally, we include cases where $\sigma_{m}=0$ (no measurement error in the survey, just rounding) and in which $\sigma_{m}$ is quite large (two tenths of a percentage point). In every case, the empirical size of the test is between 3.8 and 7.9 percent, meaning that any size distortions are very modest. This leads us to conclude that our finding that $\gamma$ is significantly different from zero for the core CPI release is not simply the artifact of some size distortion caused by measurement error and/or rounding in the survey.

\section{Conclusion}

Our results suggest that market participants might be focusing irrationally on the headline number, as opposed to the most precise available data in a data release. And, while this does not necessarily imply that irrationality of market participants explains a large share of overall asset price movements, reading the text of the data release seems to be something that should be extraordinarily easy for the markets. To the extent that we find evidence that they may not do this, it motivates work outside of models of rational asset pricing. Some recent research in macroeconomics and finance has discussed the possibility of "rational inattention" in which agents optimally choose not to collect information because it is costly to do so (e.g. Sims, 2006). Looking up the unrounded number in an anticipated and closely-watched data release is surely not costly. Accordingly, if some investors are looking only at the headline number, this seems more like irrational inattention to us. 


\section{References}

Balduzzi, Pierluigi, Edwin J. Elton and Clifton T. Green (2001): Economic News and Bond Prices: Evidence from the U.S. Treasury Market. Journal of Financial and Quantitative Analysis, 36, pp. 523-543.

Lamont, Owen A. and Richard H. Thaler (2003): Can the Market Add and Subtract? Mispricing in Tech Stock Carve-Outs, Journal of Political Economy, 111, pp. 227-268.

Sims, Christopher A. (2006): Rational Inattention: Beyond the Linear-Quadratic Case, American Economic Review, 96, pp. 158-163.

Veronesi, P. (1999): Stock Market Overreaction to Bad News in Good Times: A Rational Expectations Equilibrium Model, Review of Financial Studies, 12, pp. 975-1007. 
Table 1: Summary Statistics on Data Surprises

\begin{tabular}{|c|c|c|c|}
\hline Announcement & $\begin{array}{l}\text { Standard Deviation of } \\
\text { MMS Expectations }\end{array}$ & $\begin{array}{c}\text { Standard Deviation } \\
\text { of Surprises }\end{array}$ & $\begin{array}{l}\text { Standard Deviation } \\
\text { of Rounding Error }\end{array}$ \\
\hline $\mathrm{CPI}(\text { core })^{1}$ & 0.05 & 0.10 & 0.03 \\
\hline PPI (core) $)^{2}$ & 0.08 & 0.27 & 0.03 \\
\hline Unemployment Rate ${ }^{3}$ & 0.98 & 0.14 & 0.03 \\
\hline
\end{tabular}

${ }^{1}$ Percentage points, month-over-month. Sample July 1991 to September 2006.

2 Percentage points, month-over-month. Sample April 1997 to September 2006

${ }^{3}$ Percentage points. Sample July 1991 to September 2006.

Table 2: Responses of Asset Prices to Data Surprises and Rounding Errors

\begin{tabular}{cccc}
\hline \hline Asset Return & Announcement & Surprise & Rounding Error \\
\hline Change in & CPI (core) & $18.54^{* * * *}$ & $-16.10^{* *}$ \\
two-year yield & & $(2.71)^{* * *}$ & $(7.16)$ \\
& PPI (core) & $3.56^{* *}$ & 3.76 \\
& & $(1.13)^{* * *}$ & $(7.45)$ \\
& Unemployment Rate & $-11.67^{* * *}$ & 6.19 \\
& & $(3.00)$ & $(16.05)$ \\
Change in & CPI (core) & $19.68^{* * *}$ & $-23.11^{* *}$ \\
ten-year yield & & $(2.69)^{* *}$ & $(9.66)$ \\
& PPI (core) & $4.22^{* * *}$ & 7.19 \\
& & $(0.83)^{* *}$ & $(7.04)$ \\
& Unemployment Rate & $-7.38^{* * *}$ & -2.35 \\
& & $(2.39)$ & $(13.61)$ \\
Change in & CPI (core) & $20.27^{* * *}$ & $-19.92^{* *}$ \\
eurodollar & \multirow{2}{*}{ PPI (core) } & $(3.04)^{* * *}$ & $(8.12)$ \\
futures rate & & $5.29^{* *}$ & 2.91 \\
& & $(1.21)^{* * *}$ & $(8.49)$ \\
& Unemployment Rate & $-13.89^{* * *}$ & 8.59 \\
& & $(3.89)$ & $(18.85)$ \\
\hline \hline
\end{tabular}

Notes: Included regressors are those released at 8.30 am on any given day and are measured as the difference between unrounded released and expected values. Standard errors shown in parentheses are White heteroskedasticity robust standard errors. *** indicates significance at the 1-percent level, $* *$ at the 5-percent level and * at the 10percent level. Constant term included but not shown and insignificantly different from zero. Regressions include coefficients on the surprise components of concurrently released non-farm payrolls, retail sales and initial jobless claims, which are all significantly different from zero but not shown. 
Table 3: Responses of Asset Prices to CPI and PPI Surprises and Rounding Errors

\begin{tabular}{cccc}
\hline \hline Asset Return & Announcements & Surprise & Rounding Error \\
\hline Change in & CPI (core) and & $1.14^{* * *}$ & $-1.74^{* * *}$ \\
two-year yield & PPI (core) & $(0.21)$ & $(0.67)$ \\
& & & \\
Change in & CPI (core) and & $1.31^{* * *}$ & $-2.78^{* * *}$ \\
ten-year yield & PPI (core) & $(0.20)$ & $(1.02)$ \\
Change in & CPI (core) and & $1.50^{* * *}$ & $-2.44^{* * *}$ \\
eurodollar & PPI (core) & $(0.23)$ & $(0.74)$ \\
futures rate & & & \\
\hline \hline
\end{tabular}

Notes: The surprise and rounding error regressors have been divided by the standard deviation of surprises of the respective announcement variable (see Table 1 for these values). A common coefficient is estimated for the response of asset markets to a onestandard deviation surprise to CPI (core) and PPI (core), and another common coefficient for the response to the rounding error proportional to a one-standard deviation surprise. All other details are as described in the notes to Table 1. 
Table 4: Monte Carlo rejection rates from simulation experiment with different parameter values (effective size in percentage points for test with 5 percent nominal size).

\begin{tabular}{|c|c|c|c|c|c|c|c|c|c|c|c|c|c|c|c|c|c|}
\hline & & \multicolumn{4}{|c|}{$\sigma_{x}=0.05$} & \multicolumn{4}{|c|}{$\sigma_{x}=0.1$} & \multicolumn{4}{|c|}{$\sigma_{\mathrm{x}}=0.2$} & \multicolumn{4}{|c|}{$\sigma_{x}=0.5$} \\
\hline & & \multicolumn{16}{|c|}{$\mathrm{T}=100$} \\
\hline$\sigma_{\mathrm{m}}$ & & 0 & 0.05 & 0.1 & 0.2 & 0 & 0.05 & 0.1 & 0.2 & 0 & 0.05 & 0.1 & 0.2 & 0 & 0.05 & 0.1 & 0.2 \\
\hline \multicolumn{18}{|l|}{$R_{P O P}^{2}$} \\
\hline 0.1 & 0.05 & 6.5 & 6.2 & 6.2 & 6.3 & 6.9 & 7.3 & 7.3 & 7.5 & 5.0 & 5.4 & 5.4 & 5.8 & 6.2 & 6.1 & 6.1 & 6.4 \\
\hline 0.1 & 0.1 & 6.6 & 6.5 & 6.5 & 6.2 & 4.0 & 4.1 & 4.6 & 4.2 & 5.3 & 5.3 & 5.8 & 5.8 & 6.5 & 6.4 & 6.5 & 6.4 \\
\hline 0.1 & 0.2 & 6.1 & 5.5 & 5.8 & 5.8 & 6.3 & 6.0 & 6.7 & 6.7 & 6.1 & 6.2 & 5.8 & & .5 & 6.7 & 6.5 & 6.3 \\
\hline 0.1 & 0.5 & 6.1 & 6.1 & 6.2 & 6.5 & 5.8 & 5.4 & 4.9 & 5.2 & 5.6 & 5.6 & 6.0 & & .2 & 5.1 & 5.1 & 5.2 \\
\hline 0.2 & 0.05 & 6.9 & 6.0 & 5.9 & 5.9 & 7.1 & 7.5 & 7.8 & 7.7 & 5.0 & 5.2 & 5.2 & 5.9 & 6.2 & 6.1 & 6.2 & 6.2 \\
\hline 0.2 & 0.1 & 6.9 & 6.1 & 6.2 & 6.0 & 3.9 & 4.2 & 4.0 & 4.4 & 5.4 & 5.4 & 5.6 & 5.8 & 6.3 & 6.2 & 6.4 & 6.2 \\
\hline 0.2 & 0.2 & 5.5 & 6.1 & 5.9 & 5.7 & 6.5 & 6.3 & 6.3 & 6.5 & 6.1 & 6.0 & 5.5 & 5.9 & 6.4 & 6.7 & 6.8 & 6.1 \\
\hline 0.2 & 0.5 & 6.3 & 5.4 & 6.3 & 6.7 & 5.8 & 5.2 & 4.7 & 5.0 & 5.5 & 5.9 & 6.3 & 6.3 & 5.2 & 5.1 & 5.4 & 5.2 \\
\hline 0.3 & 0.05 & 7.0 & 5.8 & 5.6 & 5. & 7.1 & 7.8 & 7.7 & 7.8 & 5.3 & 5.3 & 5.5 & 5.9 & 5.2 & 6.1 & 6.2 & 6.4 \\
\hline 0 & & & 6.3 & 6.0 & & & 4.0 & 4.0 & 4 & & 5.3 & 6.0 & & & 6.3 & 6.7 & 6.3 \\
\hline 0 & & & 5.7 & 5.7 & & & 6.4 & 6.4 & 6.9 & 6. & 6.0 & 5.6 & & & 6.8 & 6.7 & \\
\hline 0.3 & 0 & 6 & 5.8 & 6.3 & 6. & 5 & 5.3 & 4.8 & 5.2 & 5. & 6.3 & 6.2 & & & 4.8 & 5.5 & 5.0 \\
\hline 0.4 & 0.05 & 6.7 & 5.5 & 5.2 & 5.8 & 7. & 7.6 & 7.9 & 7.6 & 5.3 & 5.0 & 5.5 & & 1 & 6.1 & 6.1 & 6.0 \\
\hline 0.4 & 0.1 & 7.3 & 6.3 & 6.3 & 5. & 4.1 & 3.8 & 3.9 & 4.4 & 5.4 & 5.2 & 6.0 & & .4 & 6.3 & 6.5 & 6.1 \\
\hline 0.4 & 0.2 & 6.1 & 5.4 & 6.0 & 6.2 & 7.1 & 6.3 & 6.7 & 6.5 & 6.2 & 6.3 & 5.5 & 5. & 6.3 & 6.8 & 6.6 & 5.4 \\
\hline 0.4 & 0.5 & 6.7 & 6.2 & 6.1 & 6.4 & 5.9 & 5.3 & 4.6 & 5.3 & 5.3 & 6.7 & 6.6 & 6.7 & 5.1 & 4.9 & 5.6 & 5.1 \\
\hline \multicolumn{18}{|c|}{$\mathrm{T}=2$} \\
\hline$\sigma_{\mathrm{m}}$ & & 0 & 0.05 & 0.1 & 0.2 & 0 & 0.05 & 0.1 & 0.2 & 0 & 0.05 & 0.1 & 0.2 & 0 & 0.05 & 0.1 & 0.2 \\
\hline \multicolumn{18}{|c|}{$\begin{array}{ll}R_{\mathrm{POP}}^{2} & \sigma_{\mathrm{e}}\end{array}$} \\
\hline 0.1 & 0.05 & 4.7 & 4.9 & 4.4 & 4.1 & 7.6 & 7.2 & 7.3 & 6.5 & 6.2 & 6.5 & 6.3 & & 5.7 & 5.9 & 5.9 & 6.0 \\
\hline 0 & 0.1 & 4.9 & 5.1 & 5.5 & 4.9 & 5.5 & 5.8 & 5.1 & 5.7 & 5.6 & 5.3 & 5.3 & 5.3 & 5.9 & 5.8 & 5.4 & 5.1 \\
\hline 0 & 0.2 & 5.5 & 6.1 & 5.6 & 5.6 & 4.4 & 4.3 & 4.4 & 4.1 & 5.8 & 5.7 & 5.9 & & 4.5 & 4.6 & 4.7 & 4.1 \\
\hline & 0.5 & & 6.7 & 6.9 & 6 & & 5.7 & 5.9 & 6. & 5. & 5.4 & 5.0 & & & 5.7 & 5.8 & 6.0 \\
\hline & 0.05 & 4.6 & 4.8 & 4.4 & 4. & & 6.6 & 6.5 & 6. & 6. & 6.2 & 6.0 & & & 5.8 & 5.9 & 6.1 \\
\hline 0 & 0.1 & 4.8 & 5.2 & 5.0 & 5. & 5. & 5.8 & 4.8 & 5.3 & 5.7 & 5.6 & 5.3 & 4.9 & 5.8 & 5.8 & 5.3 & 5.2 \\
\hline 0 & 0 & 5.4 & 5.8 & 5.7 & 5. & 4.4 & 4.3 & 4.7 & 4.4 & 5.9 & 6.0 & 6.1 & 6.5 & 4.5 & 4.4 & 4.3 & 4.0 \\
\hline 0 & 0 . & 7.2 & 6.4 & 6.7 & 6. & 5. & 5.9 & 6.0 & 6.3 & 5.1 & 5.3 & 5.2 & 5 & 6 & 6.0 & 6.0 & 6.2 \\
\hline 0 & 0.05 & 4.4 & 4.8 & 4.4 & 4. & 7.4 & 6.3 & 6.3 & 6.1 & 6.3 & 6.3 & 6.0 & .0 & 5.8 & 5.8 & 6.1 & 6.1 \\
\hline 0 & 0.1 & 5.1 & 5.8 & 6.1 & 6.2 & 5.5 & 5.9 & 4.7 & 4.8 & 5.7 & 5.4 & 5.3 & 4.1 & 5.8 & 5.5 & 5.1 & 5.1 \\
\hline 0 & 0.2 & 4.9 & 5.6 & 5.4 & 5. & 4.4 & 4.7 & 4.9 & 4.4 & 6.0 & 6.0 & 6.5 & & 4.6 & 4.4 & 4.2 & 4.3 \\
\hline & 0.5 & 7.0 & 6.2 & 6.4 & 6.4 & 5. & 5.8 & 6.1 & 5. & 5.3 & 5.6 & 5.2 & & & 5.8 & 5.9 & 6.3 \\
\hline & 0.05 & 4.7 & 5.0 & 4.8 & 4.5 & 7. & 6.4 & 6.3 & 5. & 6. & 6.3 & 5.9 & & & 5.8 & 6.3 & \\
\hline & 0.1 & 5.1 & 5.8 & 6.4 & 6. & 5. & 5.7 & 4.8 & 4. & 5.6 & 5.2 & 5.3 & 4. & 5.8 & 5.5 & 5.4 & 5.2 \\
\hline & 0 . & 5.2 & 5.5 & 5. & 5. & 4. & 4.9 & 4.6 & 4. & 6.0 & 6.1 & 6.5 & 6 & 4.5 & 4.3 & 4.0 & 5.0 \\
\hline 0.4 & 0.5 & 7.0 & 5.9 & 6.3 & 6.6 & 5.3 & 5.8 & 6.1 & 5.7 & 5.5 & 5.8 & 6.2 & 6.2 & 5.8 & 5.7 & 5.8 & 6.3 \\
\hline
\end{tabular}


Figure 1: Reactions of Asset Prices in Specifications (1) and (2)

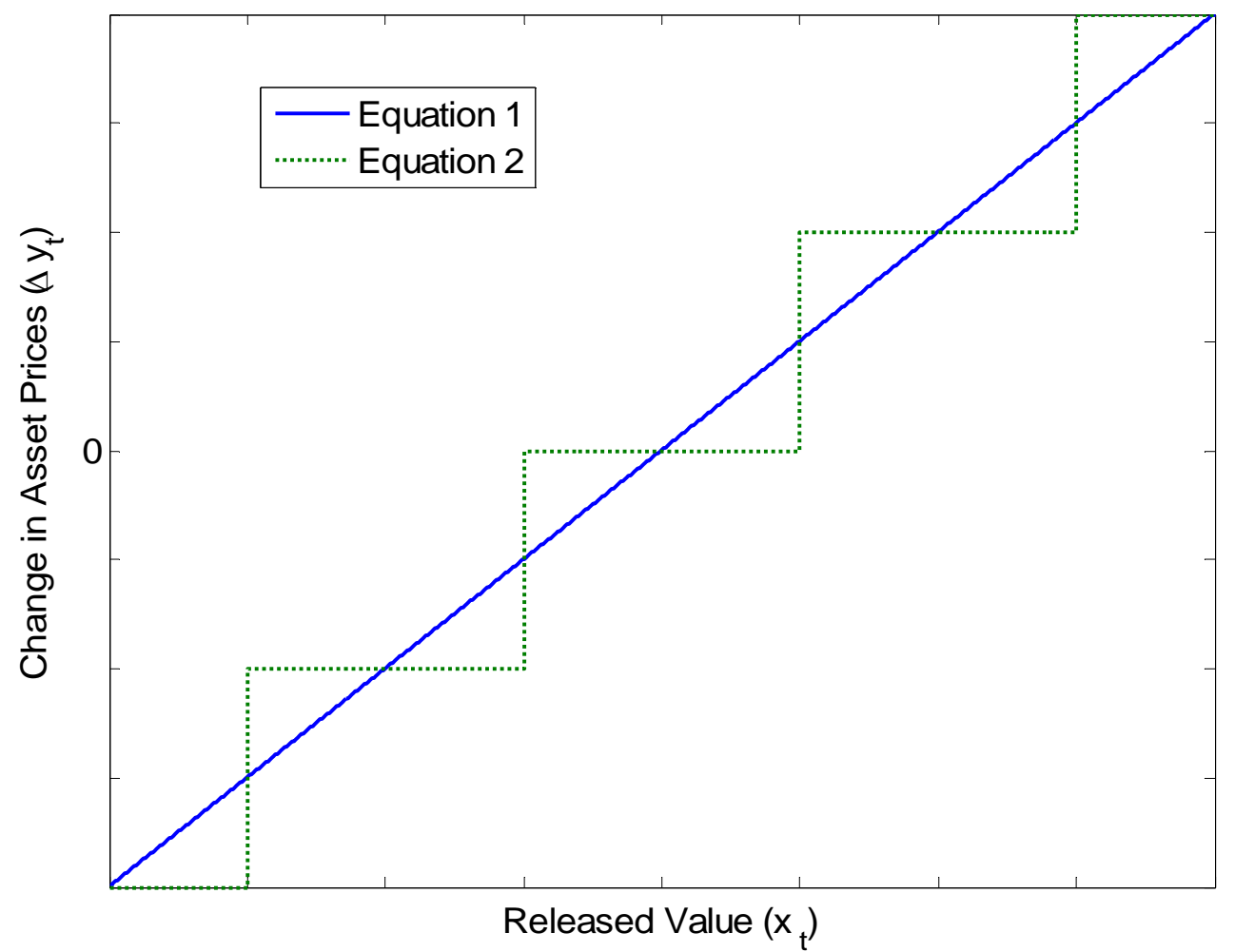

Notes: This graph plots the relationship between the released value, $x_{t}$, and the expected change in asset prices, $\Delta y_{t}$, under specification (1) (the solid line), according to which asset prices react to the unrounded number, and under specification (2) (the dotted line), according to which asset prices react to the rounded number only. 